\title{
Evaluating 18s-rRNA LAMP and selective whole genome amplification (sWGA) assay in detecting asymptomatic Plasmodium falciparum infections in blood donors
}

\author{
Enoch Aninagyei ${ }^{1,4^{*}} \mathbb{D}$, Stella Smith-Graham², Alex Boye ${ }^{3}$, Alexander Egyir-Yawson ${ }^{1}$
} and Desmond Omane Acheampong ${ }^{1 *}$

\begin{abstract}
Background: Undesirable consequences of donor Plasmodium falciparum parasitaemia on stored donor blood have been reported. Therefore, it is imperative that all prospective blood donors are screened for $P$. falciparum infections using sensitive techniques. In this study, the sensitivities of microscopy, rapid diagnostic test (RDT), loop-mediated isothermal amplification (LAMP) assay and selective whole genome amplification (sWGA) technique in detecting $P$. falciparum infections in blood donors was assessed.

Methods: Randomly selected blood donors from 5 districts in Greater Accra Region of Ghana were screened for asymptomatic P. falciparum infections. Each donor sample was screened with SD Bioline RDT kit for P. falciparum histidine rich protein 2 and Plasmodium lactate dehydrogenase antigens, sWGA and 18s-rRNA LAMP. Crude DNA LAMP (crDNA-LAMP) was compared to purified DNA LAMP (pDNA-LAMP).

Results: A total of 771 blood donors were screened. The respective overall prevalence of $P$. falciparum in Ghana by microscopy, RDT, crDNA-LAMP, pDNA-LAMP and sWGA was 7.4\%, 11.8\%, 16.9\%, 17.5\% and 18.0\%. Using sWGA as the reference test, the sensitivities of microscopy, RDT, crDNA-LAMP and pDNA-LAMP were 41.0\% (95\% Cl 32.7-49.7), 65.5\% (95\% Cl 56.9-73.3), 82.6\% (95\% Cl 75.8-88.3) and 95.7\% (95\% Cl 90.1-98.4), respectively. There was near perfect agreement between LAMP and sWGA (sWGA vs. crDNA-LAMP, $K=0.87$; sWGA vs. pDNA-LAMP, $K=0.96$ ), while crDNALAMP and pDNA-LAMP agreed perfectly $(k=0.91)$. Goodness of fit test indicated non-significant difference between the performance of LAMP and sWGA (crDNA-LAMP vs. sWGA: $x^{2}=0.71, p=0.399$ and pDNA-LAMP vs. sWGA: $x^{2}=0.14$, $p=0.707$ ). Finally, compared to sWGA, the performance of LAMP did not differ in detecting sub-microscopic parasitaemia (sWGA vs. crDNA-LAMP: $x^{2}=1.12, p=0.290$ and sWGA vs. pDNA-LAMP: $x^{2}=0.22, p=0.638$ ).

Conclusions: LAMP assay agreed near perfectly with sWGA with non-significant differences in their ability to detect asymptomatic P. falciparum parasitaemia in blood donors. Therefore, it is recommended that LAMP based assays are employed to detect $P$. falciparum infections in blood donors due to its high sensitivity, simplicity, cost-effectiveness and user-friendliness.
\end{abstract}

Keywords: 18s-rRNA-LAMP, Crude DNA LAMP, Purified DNA LAMP, Selective whole genome amplification, $P$. falciparum histidine rich protein 2, Plasmodium lactate dehydrogenase, Diagnostic indices, Crude DNA extraction

\footnotetext{
*Correspondence: enochaninagyei@yahoo.com;

dacheampong@ucc.edu.gh

${ }^{1}$ Department of Biomedical Sciences, School of Allied Health Sciences,

University of Cape Coast, Cape Coast, Ghana

Full list of author information is available at the end of the article
} 


\section{Background}

In Ghana, the prevalence of asymptomatic Plasmodium falciparum infections is shown to be high among persons over 20-year-old [1] and prospective blood donors [2]. In other parts of Africa, high prevalence of asymptomatic $P$. falciparum parasitaemia in blood donors has also been reported [3-6]. However, blood donors in most malariaendemic countries in sub-Saharan Africa (SSA) are not tested for malaria [7], despite World Health Organization (WHO) recommendations that all blood donors should be tested for malaria parasites [8].

While some authors have reported that $P$. falciparum can persist for months or years in blood presents a risk to prospective recipients $[9,10]$, however, others have also argued that the parasite may survive refrigeration for few days $[11,12]$. Notwithstanding the ambiguity surrounding the transmissibility of Plasmodium parasite through blood transfusion, previous studies have also found storage related untoward haematological and biochemical changes in malaria infected blood donor units [13]. Due to the negative changes impacted to all haematological cell lines and the accumulation of harmful products, it is imperative that all prospective blood donors are screened for malaria parasites to exclude infected donor blood from clinical use. To be able to detect low parasitaemia associated with asymptomatic infections, a sensitive diagnostic technique that is easy to adopt and amenable to blood banks in malaria endemic zones is essential in this regard.

Blood smears are the most utilized method to detect Plasmodium parasitaemia. However, this method is limited by its sensitivity and its absolute dependence on the operator. Again, blood smears cannot be performed as a high throughput test due to the huge numbers of donor blood units that are processed by blood banks daily [14]. Due to the aforementioned, there is currently no screening test that is fast, practical, affordable and suitably sensitive for blood banks [15].

LAMP is a multi-primer molecular assay which in comparison to polymerase chain reaction (PCR) is cheaper, simpler and faster, taking out three disadvantages of PCR. LAMP method relies on auto cycling strand-displacement DNA synthesis mediated by Bst DNA polymerase enzyme. The principal merit of this method is that LAMP can amplify target DNA without prior denaturation of the DNA template because Bst DNA polymerase can be activated at isothermal temperatures to perform DNA template strand displacement and thus the LAMP reactions can be conducted at temperatures $60-65^{\circ} \mathrm{C}$ [16].

Selective whole genome amplification (sWGA) technique has been used to increase sub-microscopic DNA levels of Plasmodium parasites from infected blood samples $[17,18]$ and $P$. falciparum genomes from dried blood spots [19]. SWGA preferentially amplifies DNA of pathogens from target and host DNA mixture [20]. SWGA technology is similar to PCR in that a specific portion of the DNA in a sample is enriched. Amplifying an entire genome by SWGA differs technically from amplifying a single gene region by PCR. The two techniques differ by how primers are chosen and the amplification conditions used. The primers used for SWGA bind to DNA sequence motifs that are common in the target genome but not the genomes of other contaminating DNA. The SWGA procedure takes advantage of the inherent differences in the frequencies of sequence motifs among species to designed primers specific to a target species. These primers are then used to selectively amplify the target genomes using phi29 multi-displacement amplification technology [21]. The phi29 polymerase is strand displacing and amplifies DNA from primers with high processivity (up to 70-kbp fragments) and is 100 times less error prone than Taq [22]. Considering the merits of LAMP and sWGA, this study explored these two nucleic acid amplification techniques together with microscopy and RDT in detecting asymptomatic falciparum parasitaemia in blood donors.

\section{Methods}

\section{Study design}

The study involved screening of randomly selected blood donors in selected districts in the Regional capital of Ghana. After obtaining donor consent, blood samples were collected into $\mathrm{K}_{2}$-EDTA tube. Each donor sample was screened for $P$. falciparum histidine rich protein 2 (PfHRP2) and Plasmodium lactate dehydrogenase $(\mathrm{pLDH})$ proteins. Four dry blood spots were prepared for each sample and the remaining whole blood stored at $4{ }^{\circ} \mathrm{C}$. Each $P$. falciparum positive sample was confirmed by both crude DNA LAMP (crDNA-LAMP) and purified DNA LAMP (pDNA-LAMP) and by selective Whole Genome Amplification (sWGA). Negative RDT and microscopy samples were screened with molecular techniques in pools of 10 samples. Each positive sample pool was resolved by screening each sample individually.

\section{Blood donor selection, specimen collection and markers screening}

Blood donors were recruited in collaboration with the National Blood Service, Ghana, according to national protocols and ethics. Random blood donor samples were collected from five different randomly selected districts in the Greater Accra region, Ghana. Blood donors were sampled from November 2017 to July 2018. All donor specimens included in the study were negative for transfusion-transmissible infections (hepatitis B virus, hepatitis $\mathrm{C}$ virus, HIV I\&II and Treponema pallidum). Five 
milliliter of donor blood was aseptically collected into $\mathrm{K}_{2}$-EDTA tubes. EDTA samples were either processed immediately or stored at $4-6{ }^{\circ} \mathrm{C}$ till ready to be processed.

\section{Specimen processing, screening and transport}

$\mathrm{K}_{2}$-EDTA donor blood specimens were screened for malaria parasites using SD Bioline PfHRP2/pLDH rapid diagnostic test kit (Gyeonggi-do, Republic of Korea). Thick and thin blood films were made in triplicates and labelled after which dry blood spots (DBS) were prepared for each sample, packaged, labelled and stored at room temperature till they were shipped to Wellcome Sanger Institute, Hinxton, UK for Plasmodium parasite detection through genome sequencing using high throughput Hiseq Amplicon Sequencing technique. Morphological identification and parasitaemia were determined for Plasmodium parasites using 3\% Giemsa staining as described elsewhere [23]. Parasitaemia was estimated by dividing the number of asexual parasites per at least 200 leukocytes and multiplied by the estimated baseline $\mathrm{WBC}$ of the patients/ $\mu \mathrm{L}$ of blood [24].

\section{Crude Plasmodium parasite DNA (crDNA) extraction}

Crude DNA was extracted by the boil and spin method as described by Foundation for Innovation Diagnostics, Geneva, Switzerland [25]. In brief, $60 \mu \mathrm{L}$ of each well mixed donor whole blood, positive and negative control samples were transferred into separate $1.5 \mathrm{~mL}$ Eppendorf tubes pre-filled with $60 \mu \mathrm{L}$ of extraction buffer $(400 \mathrm{mM}$ $\mathrm{NaCl}, 40 \mathrm{mM}$ Tris pH 6.5, 0.4\% SDS). The samples were mixed with the extraction buffer by vortex for $10 \mathrm{~s}$. The tubes were then placed in water bath at $95{ }^{\circ} \mathrm{C}$ for $5 \mathrm{~min}$, after which the tubes were centrifuged at $10,000 \mathrm{rpm}$ for $3 \mathrm{~min}$. About $30 \mu \mathrm{L}$ of the clear supernatant was subsequently transferred to a dilution tube pre-filled with $270 \mu \mathrm{L}$ of sterile nuclease free water. Crude DNA samples were stored at $-20^{\circ} \mathrm{C}$ till ready for amplification.

\section{Pure DNA ( $p D N A$ ) extraction using modified Boom's method}

Donor whole blood $(250 \mu \mathrm{L})$ were dispensed into $2-\mathrm{mL}$ sterile Eppendorf tubes containing $250 \mu \mathrm{L}$ of lysis buffer (1.6 M GuHCl, $60 \mathrm{mM}$ Tris $\mathrm{pH}$ 7.4, 1\% Triton X-100, $60 \mathrm{mM}$ EDTA, Tween-20 10\%), $50 \mu \mathrm{L}$ Proteinase-K and $250 \mu \mathrm{L}$ glass beads). The mixtures were incubated horizontally in a shaker $(200 \mathrm{rpm})$ at $65^{\circ} \mathrm{C}$ overnight. To capture DNA, $250 \mu \mathrm{L}$ of diatomaceous earth solution $(1.0 \mathrm{~g}$ diatomaceous earth (Sigma Aldrich Chemi $\mathrm{GmbH}$ ) in $5.0 \mathrm{~mL}$ of $\mathrm{H}_{2} \mathrm{O}$ containing $50 \mu \mathrm{L}$ of $37 \%$ (wt/vol) $\mathrm{HCl}$ was added to the suspensions and incubated at $37{ }^{\circ} \mathrm{C}$ with shaking $(200 \mathrm{rpm})$ for $60 \mathrm{~min}$. The mixtures were centrifuged at $14,000 \mathrm{rpm}$ for $10 \mathrm{~s}$ and the resulting pellets were washed twice with $900 \mu \mathrm{L}$ of $70 \%$ ethanol $\left(2-8{ }^{\circ} \mathrm{C}\right)$ followed by $900 \mu \mathrm{L}$ of acetone. The pellets were dried at $50{ }^{\circ} \mathrm{C}$ for $20 \mathrm{~min}$ and re-suspended in $100 \mu \mathrm{L}$ of nuclease free water and centrifuged at $14,000 \mathrm{rpm}$ for $10 \mathrm{~s}$. The purified genomic DNA was stored at $4{ }^{\circ} \mathrm{C}$ and later used as templates for malaria LAMP assays. Positive and negative extraction controls were done alongside with the donor blood samples.

\section{Detection of $18 \mathrm{~S}$ rRNA by crDNA and pDNA LAMP}

The LAMP primers used in this study were designed by Poon et al. [26]. The LAMP assay detects the $18 \mathrm{~S}$ rRNA target in human Plasmodium parasites. In brief, the LAMP reaction volumes were made up of $12.5 \mu \mathrm{L}$ of reaction mix, $1 \mu \mathrm{L}, 2.6 \mu \mathrm{L}$ and $1 \mu \mathrm{L}$ of fluorescent detector, primer mix, Bst DNA polymerase respectively (Eiken Chemical, Japan), $2.9 \mu \mathrm{L}$ of nuclease free water and $5 \mu \mathrm{L}$ of the crDNA or pDNA extract in $0.2 \mathrm{~mL}$ PCR tubes (Fisher Scientific, USA). DNA was amplified, together with 4 extraction controls [2 negative controls (nuclease free water) and 2 positive controls (Plasmodium specimen with parasite count of 8000 parasites $/ \mu \mathrm{L}$ of blood)], on thermal cycler (Veriti, USA) at constant temperature of $65^{\circ} \mathrm{C}$ for $1 \mathrm{~h}$ and the Bst DNA polymerase inactivated at $80{ }^{\circ} \mathrm{C}$ for $5 \mathrm{~min}$. The final reaction results were determined by visual examination of the final greenish yellow colour development. A light brown final colour signified a negative reaction.

\section{Plasmodium falciparum primer design and probe selection} Plasmodium falciparum genome primers (probes) were designed to preferentially bind to the $P$. falciparum genome (P. falciparum 3D7 genome) using PERL script published by Leichty and Brisson [20] was used to select up to 100 (8-12 mer) primers with a predicted specified melting temperature $\left(\leq 30{ }^{\circ} \mathrm{C}\right)$. Top 50 primers with the highest desired/contaminating $(\mathrm{D} / \mathrm{C})$ ratios were selected for further analysis. From these 50, primers with more than three complementary nucleotides at $3^{\prime}$ and $5^{\prime}$ ends were removed to prevent formation of hairpin structures. To prevent primer-primer dimerization, primer pairs with more than three complementary nucleotides at their ends were also removed. A final 28 primers that passed quality control checks were ordered from Integrated DNA Technologies (Coralville, IA) as standard desalting purification with a single modification of phosphorothioate bond between the last two $3^{\prime}$ nucleotides to prevent primer degradation by the Phi29 polymerase exonuclease activity. Individual primers were reconstituted in Tris $\mathrm{HCl}(\mathrm{pH} 8.0)$ buffer and pooled into three sets (probes) following the $\mathrm{D} / \mathrm{C}$ ranking described above: the first set consisted of the first 10 primers (Probe_10), the second set consisted of the first 20 primers (Probe_20), and the third set consisted of all 28 primers (Probe_28). 
The primers used to specifically identify $P$. falciparum in donor blood samples were published by Oyola et al. [27].

\section{Selective whole genome amplification (sWGA) assay}

Selective whole genome amplification (sWGA) was used to detect Plasmodium parasites in dry blood samples based on published primers and probes [27]. Briefly, Plasmodium DNA in dry blood spot (DBS) samples were extracted using QIAamp DNA Investigator Kit (Qiagen, Germany) following the manufacturer's protocol. The sWGA reaction was performed in $0.2 \mathrm{~mL}$ PCR plates in a reaction volume of $50 \mu \mathrm{L}$ containing at least $5 \mathrm{ng}$ of template DNA, $1 \times$ BSA, $1 \mathrm{mM}$ dNTPs, $2.5 \mu \mathrm{M}$ of each amplification primer, $1 \times$ Phi29 reaction buffer and 30 units of Phi29 polymerase enzyme (New England Biolabs). Amplification was done in "stepdown" protocol consisting of $35^{\circ} \mathrm{C}$ for $5 \mathrm{~min}, 34{ }^{\circ} \mathrm{C}$ for $10 \mathrm{~min}, 33^{\circ} \mathrm{C}$ for $15 \mathrm{~min}, 32{ }^{\circ} \mathrm{C}$ for $20 \mathrm{~min}, 31{ }^{\circ} \mathrm{C}$ for $30 \mathrm{~min}, 30{ }^{\circ} \mathrm{C}$ for $16 \mathrm{~h}$ then heating at $65{ }^{\circ} \mathrm{C}$ for $15 \mathrm{~min}$ to inactivate the enzymes prior to cooling to $4{ }^{\circ} \mathrm{C}$. Preceding sequencing, sWGA products were cleaned using Ampure XP beads (Beckman Coulter, UK) and 1.8 volumes of beads per 1 volume of sample were mixed and incubated for $5 \mathrm{~min}$ at room temperature. After which the bead/DNA mixture was placed on a magnetic rack to capture the DNAbound beads. Beads were washed twice with $200 \mu \mathrm{L}$ of $80 \%$ ethanol and the bound DNA eluted with $60 \mu \mathrm{L}$ of elution buffer. Cleaned amplified DNA products (approx. $0.5-1 \mu \mathrm{g}$ DNA) were used to prepare DNA library using the NEBNext DNA sample preparation kit (New England Biolabs) for high throughput sequencing. DNA libraries were sequenced using Illumina HiSeq 2500 DNA Sequencer.

\section{Analysis of sequence data}

Identification of $P$. falciparum using sWGA sequence data has been reported by Oyola et al. [27]. Plasmodium falciparum sequence reads were analysed and no human DNA reads were involved in the process. In brief, sequence reads were demultiplexed and fastq data files were generated downstream automatically using the onboard PC. Subsequently, reads were first trimmed of low-quality bases from their ends using BioEdit v7.2 after sequence data for each sample was subjected to standard Illumina QC procedures. Approximately, 20 million reads per sample was subjected to detailed analysis for enrichment, quality, content, and coverage. Each dataset was analysed independently by mapping sequence reads to the 3D7 reference genome using Burrows-Wheeler Aligner (BWA) [28]. Subsequently, SAMtools [29] was used to generate coverage statistics from the BWA mapping output. A list of over 1.2 million high-quality singlenucleotide polymorphism (SNP) positions, which were not filtered by gene class or region, but on individual properties of SNPs were used. Genotyping of $P$. falciparum by sWGA was performed using Mpileup to count alleles present in at least five reads (alleles with less than five reads were discarded).

\section{Data analysis}

Percentages were calculated by simple proportions. Prevalence of malaria by each diagnostic technique was done by dividing the number of samples found to be infected by the number of tests done (formula indicated below). The sensitivities, specificities, positive and negative predictive values were determined based on the formulae below and their respective 95\% confidence internals as well as the inter-diagnostic technique test of agreement (Cohen's kappa test of agreement) of each technique were determined by SPSS Version 24 (Chicago, IL, USA).

$$
\begin{aligned}
& \text { Sensitivity }=\text { true positive/ } \\
& \text { (true positive }+ \text { false negative) } \times 100 \% \\
& \text { Specificity }=\text { true negative } / \\
& \text { (true negative }+ \text { false positive) } \times 100 \% \\
& \mathrm{PPV}=\text { true positive } / \text { (true positive }+ \text { false positive) } \times 100 \% \\
& \mathrm{NPV}=\text { true negative/ } \\
& \text { (true negative }+ \text { false negative) } \times 100 \%
\end{aligned}
$$

where PPV and NPV are positive and negative predictive values respectively.

$$
\begin{aligned}
& \mathrm{P}_{(\text {technique } \mathrm{x})}=\text { number of } P \text {.falciparum infected } \\
& \text { blood donors identified by technique } \mathrm{x} / \\
& \text { total number of donors screened } \times 100 \%
\end{aligned}
$$

where $\mathrm{P}_{(\text {technique } \mathrm{x})}$ is prevalence of $P$. falciparum parasitaemia determined by either microscopy, rapid diagnostic test, LAMP (crDNA or pDNA) or sWGA.

\section{Results \\ Demographic characteristics and P. falciparum parasitaemia in the blood donors}

Microscopic, serological and molecular (LAMP and amplicon sequencing) of Plasmodium parasitaemia were done in 771 blood donors randomly selected from five districts in the Greater Accra Region of Ghana. The number of blood donors analysed in the Ada East, Ashaiman, Ayawaso, Ga South and Ga West districts were 149 (83.2\% males), 164 (82.9\% males), 155 (80.6\% males), 140 (77.2\% males) and 163 (77.9\% males), respectively. The overall mean age of the blood donors was $30.7 \pm 8.8$ years. The respective mean ages of the donors 
in each district was Ada East (32.4 \pm 9.2 years), Ashaiman (32.0 \pm 9.5 years), Ayawaso ( $29.8 \pm 9.2$ years), Ga South $(29.1 \pm 8.6$ years) and Ga West (30.1 \pm 8.9 years). The overall geometric mean of parasites density (minimum-maximum count) was 1652 parasites/ $\mu \mathrm{L}$ (5054798 parasites $/ \mu \mathrm{L}$ ) and the respective geometric mean of parasites density (minimum-maximum count) for Ada East, Ashaiman, Ayawaso, Ga South and Ga West were 2311 parasites $/ \mu \mathrm{L}$ (1578-3151 parasites $/ \mu \mathrm{L})$, 991 parasites $/ \mu \mathrm{L}$ (633-1895 parasites/ $\mu \mathrm{L}), 792$ parasites/ $\mu \mathrm{L}(505-1005$ parasites $/ \mu \mathrm{L}), 2334$ parasites/ $\mu \mathrm{L}$ (6974798 parasites/ $\mu \mathrm{L}$ ) and 1607 parasites/ $\mu \mathrm{L}(512-4105$ parasites $/ \mu \mathrm{L}$ ). Together with the aforementioned data, the highest educational level and the occupations distribution of the blood donors are presented in Table 1.

\section{Microscopic, serological and sub-microscopic prevalence of $P$. falciparum in donor blood}

The overall prevalence of $P$. falciparum in blood donors in the Greater Accra region was 7.4\% (57/771) by microscopy. The prevalence of $P$. falciparum parasitaemia in donors screened from the districts were: Ada East
(10.7\%), Ashaiman (6.1\%), Ayawaso (3.9\%), Ga South (9.3\%) and Ga West (7.4\%). The combined use of $P$. falciparum histidine-rich protein 2 (PfHRP-2) and Plasmodium lactate dehydrogenase (pLDH) rapid diagnostic test increased the overall detection rate by $4.4 \%$. With the exception of Ayawaso sub-metro where there was no increased in the detection rate of microscopy and the RDT, there was $2.4-10.0 \%$ increase in the detection rate of the RDT in other districts. Of the 91 RDT positive donor samples, both PfHRP2 and pLDH proteins were detected in $36(39.6 \%)$ of the samples. PfHRP2 antigens but not pLDH were detected in $52(57.1 \%)$ of the samples. Three parasites with HRP2 deletions were suspected. However, genotyping was not done to confirm this suspected deletions.

Loop-mediated isothermal amplification (LAMP) performed on both crude (crDNA-LAMP) and pure (pDNALAMP) Plasmodium parasite DNA extract detected more infections than microscopy and the RDT. The overall prevalence of $P$. falciparum parasitaemia in blood donors detected by crDNA-LAMP and pDNA-LAMP were $16.9 \%$ and $17.5 \%$. Across the five districts, both

Table 1 Demographic characteristics and Plasmodium falciparum count of blood donors stratified into districts

\begin{tabular}{|c|c|c|c|c|c|}
\hline $\begin{array}{l}\text { Demographic variable } \\
\text { and parasite count }\end{array}$ & $\begin{array}{l}\text { Ada East District } \\
(n=149)\end{array}$ & $\begin{array}{l}\text { Ashaiman Municipal } \\
(\mathrm{n}=164)\end{array}$ & $\begin{array}{l}\text { Ayawaso sub-metro } \\
(\mathrm{n}=155)\end{array}$ & $\begin{array}{l}\text { Ga South Municipal } \\
(n=140)\end{array}$ & $\begin{array}{l}\text { Ga West } \\
\text { Municipal } \\
(n=163)\end{array}$ \\
\hline Age mean \pm SD (years) & $32.4 \pm 9.2$ & $32.0 \pm 9.5$ & $29.8 \pm 9.2$ & $29.1 \pm 8.6$ & $30.1 \pm 8.9$ \\
\hline \multicolumn{6}{|l|}{ Gender } \\
\hline Male n (\%) & $124(83.2)$ & $136(82.9)$ & $125(80.6)$ & $108(77.2)$ & $127(77.9)$ \\
\hline Female n (\%) & $25(16.8)$ & $28(17.1)$ & $30(19.4)$ & $32(22.8)$ & $36(22.1)$ \\
\hline \multicolumn{6}{|l|}{ Highest education } \\
\hline No formal education & $7(4.7)$ & $7(4.3)$ & $4(2.6)$ & $8(5.7)$ & $1(0.6)$ \\
\hline Junior high school ${ }^{a}$ & $53(35.6)$ & $57(34.7)$ & $46(29.7)$ & $43(30.7)$ & $48(29.4)$ \\
\hline Senior high school ${ }^{b}$ & 49 (32.9) & $58(35.4)$ & 65 (41.9) & $57(40.7)$ & $56(34.4)$ \\
\hline Tertiary & $32(21.5)$ & $34(20.7)$ & $37(23.8)$ & $32(22.8)$ & $58(35.6)$ \\
\hline Other $^{c}$ & $8(5.3)$ & $8(4.9)$ & $3(1.9)$ & $0(0.0)$ & $0(0.0)$ \\
\hline \multicolumn{6}{|l|}{ Occupation } \\
\hline Student & $24(16.1)$ & $29(17.7)$ & $37(23.8)$ & $32(23.8)$ & $25(15.3)$ \\
\hline Interns & $2(1.4)$ & $2(1.2)$ & $2(1.3)$ & $0(0.0)$ & $2(1.2)$ \\
\hline Formal workers & $20(13.4)$ & $19(11.6)$ & $7(4.5)$ & $12(8.6)$ & $29(17.8)$ \\
\hline Informal workers ${ }^{d}$ & $70(47.0)$ & $79(48.2)$ & $70(45.2)$ & $66(47.1)$ & $62(38.0)$ \\
\hline Trading & $26(17.4)$ & $29(17.7)$ & $19(12.3)$ & $19(13.5)$ & $36(22.1)$ \\
\hline Security officers & $7(4.7)$ & $1(0.6)$ & $14(9.0)$ & $9(6.4)$ & $9(5.5)$ \\
\hline Unemployed & $0(0.0)$ & $5(3.0)$ & $6(3.9)$ & $2(1.4)$ & $0(0.0)$ \\
\hline \multicolumn{6}{|c|}{ Parasite density (parasites $/ \mu \mathrm{L}$ ) } \\
\hline Geometric mean & 2311 & 991 & 792 & 2334 & 1607 \\
\hline Min-max count & $1578-3151$ & $633-1895$ & $505-1005$ & $697-4798$ & $512-4105$ \\
\hline
\end{tabular}

a Middle school education inclusive

b O\&A level education inclusive

c Others include technical/vocational education

d All informal workers except traders 
LAMP assays detected more infections than individual use of microscopy and the RDT. The prevalence of $P$. falciparum infections based on crDNA-LAMP and pDNALAMP assays in each of the districts were Ada East 24.2\% and 25.5\%, Ashaiman 14.0\% (in both cases), Ayawaso $10.3 \%$ (in both cases), Ga South $20.0 \%$ and $21.4 \%$ and Ga West $16.6 \%$ and $17.2 \%$.

Selective whole genome amplification (sWGA) assay performed better than all the other diagnostic methods. With sWGA assay, the overall prevalence of $P$. falciparum parasitaemia was $18.0 \%$. The prevalence of $P$. falciparum found in Ada East, Ashaiman, Ayawaso, Ga South and Ga West were 24.8\%, 14.0\%, 11.0\%, 22.1\% and 19.0\% respectively. All the microscopy detectable specimens were also detected by the RDT and the molecular assays (Table 2). Overall prevalence of malaria sub-microscopic parasitaemia determined by RDT, crDNA-LAMP, pDNALAMP and sWGA were $4.4 \%, 9.5 \%, 10.1 \%$ and $10.6 \%$. The sub-microscopic prevalence by the diagnostic methods in the districts are presented in Table 2.

Again, in Table 2, goodness of fit test indicated significant difference between the sensitivities of microscopy $\left(x^{2}=59.0, \mathrm{p}<0.01\right)$ and $\mathrm{RDT}\left(x^{2}=20.0, \mathrm{p}<0.01\right)$ and sWGA. However, the sensitivities of LAMP and sWGA did not differ significantly [(crDNA-LAMP vs. sWGA $\left(x^{2}=0.71, \mathrm{p}=0.399\right)$ and pDNA-LAMP vs. sWGA $\left.\left(x^{2}=0.14, \mathrm{p}=0.707\right)\right]$. Comparing to sWGA, the performance of microscopy $\left(x^{2}=31.70, \mathrm{p}<0.01\right)$ differed whilst LAMP did not differ [crDNA-LAMP $\left(x^{2}=1.12\right.$, $\mathrm{p}=0.290)$ and pDNA-LAMP $\left.\left(x^{2}=0.22, \mathrm{p}=0.638\right)\right]$ in detecting sub-microscopic parasitaemia.

\section{Concordance between microscopy and RDT}

There was perfect agreement between RDT based on pLDH detection and microscopy. However, microscopy agreed with RDT based on PfHRP2 by a little over $50.0 \%$

Table 2 Prevalence of $P$. falciparum in blood donors by diagnostic technique

\begin{tabular}{|c|c|c|c|c|c|c|c|}
\hline Technique & Overall $(n=771)$ & $\begin{array}{l}\text { Ada East } \\
(n=149)\end{array}$ & $\begin{array}{l}\text { Ashaiman } \\
(n=164)\end{array}$ & $\begin{array}{l}\text { Ayawaso } \\
(n=155)\end{array}$ & $\begin{array}{l}\text { Ga South } \\
(n=140)\end{array}$ & $\begin{array}{l}\text { Ga West } \\
(n=163)\end{array}$ & $x^{2}$ ( $p$ value) \\
\hline Microscopy & & & & & & & $59.0(<0.01)$ \\
\hline Positive & $57(7.4 \%)$ & $16(10.7 \%)$ & $10(6.1 \%)$ & $6(3.9 \%)$ & $13(9.3 \%)$ & $12(7.4 \%)$ & \\
\hline Negative & $714(92.6 \%)$ & $133(89.3 \%)$ & 154 (93.9\%) & 149 (96.1\%) & 127 (90.7\%) & $151(92.6 \%)$ & \\
\hline \multicolumn{8}{|c|}{ Rapid diagnostic test } \\
\hline Total RDT ${ }^{+}$ & $91(11.8 \%)$ & $24(16.1 \%)$ & $14(8.5 \%)$ & $6(3.9 \%)$ & $27(19.3 \%)$ & $20(12.3 \%)$ & $20.0(<0.01)$ \\
\hline $\mathrm{PfHRP}^{+} / \mathrm{pLDH}^{+}$ & $36(39.6 \%)^{a}$ & $9(37.5 \%)^{\mathrm{a}}$ & $7(50.0 \%)^{a}$ & $2(33.3 \%)^{a}$ & $10(37.0 \%)^{\mathrm{a}}$ & $8(40.0 \%)^{a}$ & \\
\hline $\mathrm{PfHRP}^{+} / \mathrm{pLDH}^{-}$ & $52(57.1 \%)^{a}$ & $13(51.2 \%)^{a}$ & $7(50.0 \%)^{a}$ & $4(66.7 \%)^{a}$ & $17(63.0 \%)^{a}$ & $11(55.0 \%)^{\mathrm{a}}$ & \\
\hline $\mathrm{PfHRP}^{-} / \mathrm{pLDH}^{+}$ & $3(3.3 \%)^{\mathrm{a}}$ & $2(8.3 \%)^{\mathrm{a}}$ & $0(0.0 \%)^{\mathrm{a}}$ & $0(0.0 \%)^{\mathrm{a}}$ & $0(0.0 \%)^{\mathrm{a}}$ & $1(5.0 \%)^{\mathrm{a}}$ & \\
\hline \multicolumn{8}{|l|}{ Molecular assays } \\
\hline crDNA-LAMP & & & & & & & $0.71(0.399)$ \\
\hline Positive & $130(16.9 \%)$ & $36(24.2 \%)$ & $23(14.0 \%)$ & $16(10.3 \%)$ & $28(20.0 \%)$ & $27(16.6 \%)$ & \\
\hline Negative & $641(84.1 \%)$ & $113(78.5 \%)$ & $141(86.0 \%)$ & $139(89.7 \%)$ & $112(80.0 \%)$ & $136(83.4 \%)$ & \\
\hline pDNA-LAMP & & & & & & & $0.14(0.707)$ \\
\hline Positive & $135(17.5 \%)$ & $38(25.5 \%)$ & $23(14.0 \%)$ & $16(10.3 \%)$ & $30(21.4 \%)$ & $28(17.2 \%)$ & \\
\hline Negative & $636(82.5 \%)$ & $111(74.5 \%)$ & $141(86.0 \%)$ & $139(89.7 \%)$ & $110(78.6 \%)$ & $135(82.8 \%)$ & \\
\hline \multicolumn{8}{|l|}{ sWGA } \\
\hline Positive & $139(18.0 \%)$ & $37(24.8 \%)$ & $23(14.0 \%)$ & $17(11.0 \%)$ & $31(22.1 \%)$ & $31(19.0 \%)$ & \\
\hline Negative & $632(82.0 \%)$ & $112(75.2 \%)$ & $141(86.0 \%)$ & $138(89.0 \%)$ & $109(77.9 \%)$ & $132(81.0 \%)$ & \\
\hline \multicolumn{8}{|c|}{ Sub-microscopic donor parasitaemia } \\
\hline $\begin{array}{l}\text { Rapid diagnos- } \\
\quad \text { tic test }\end{array}$ & $34(4.4 \%)$ & $8(5.4 \%)$ & $4(2.4 \%)$ & $0(0.0 \%)$ & $14(10.0 \%)$ & $8(4.9 \%)$ & $31.70(<0.01)$ \\
\hline crDNA-LAMP & 73 (9.5\%) & $20(13.4 \%)$ & $13(7.9 \%)$ & $10(6.4 \%)$ & $15(10.7 \%)$ & $15(9.2 \%)$ & $1.12(0.290)$ \\
\hline pDNA-LAMP & $78(10.1 \%)$ & $22(14.7 \%)$ & $13(7.9 \%)$ & $10(6.4 \%)$ & $17(12.1 \%)$ & $16(9.8 \%)$ & $0.22(0.638)$ \\
\hline sWGA & $82(10.6 \%)$ & $21(14.1 \%)$ & $13(7.9 \%)$ & $11(7.0 \%)$ & $18(12.8 \%)$ & $19(11.6 \%)$ & \\
\hline
\end{tabular}

$R D T$ rapid diagnostic test, $P f H R P 2$ Plasmodium falciparum specific histidine rich protein $2, p L D H$ Plasmodium specific lactate dehydrogenase, $P f H R P 2^{+} / p L D H^{+}$both HRP2 and pLDH detected in donor blood, $P f H R P 2^{+} / p L D H^{-}$HRP2 but not pLDH detected in donor blood, $P f H R P 2^{-} / p L D H^{+}$LDH but not HRP2 detected in donor blood (HRP2 gene deletion), crDNA crude DNA extract, $p D N A$ purified DNA extract, sWGA selective whole genome amplification

a Percentages calculated from the total number of donors tested positive by the RDT

$x^{2}$ is Chi square goodness of fit test statistic. Significance level was determined at $p<0.05$ 
Table 3 Agreement between positive malaria RDT categorization and microscopy results

\begin{tabular}{llcc}
\hline RDT positive results categorization & Malaria microscopy & & \% agreement \\
\cline { 2 - 4 } & Concordant & Discordant & 100.00 \\
\hline PfHRP2 $^{+} / \mathrm{pLDH}^{+}(n=36)$ & 36 & 34 & 52.9 \\
PfHRP2 $^{-} / \mathrm{pLDH}^{-}(n=52)$ & 18 & 0 & 100.0 \\
PfHRP2 $^{-} / \mathrm{PLDH}^{+}(n=3)$ & 3 & 34 & \\
Total & 57 & $n$ & \\
\hline
\end{tabular}

$R D T$ rapid diagnostic test, $P f H R P 2$ Plasmodium falciparum specific histidine rich protein $2, p L D H$ Plasmodium specific lactate dehydrogenase, $P f H R P 2^{+} / p L D H^{+}$both

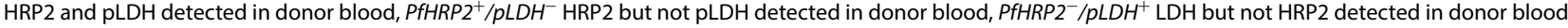
(HRP2 gene deletion)

Table 4 Diagnostic indices of the diagnostic techniques using sWGA assay as reference

\begin{tabular}{|c|c|c|c|c|c|c|c|c|}
\hline Technique & TP & $\mathrm{TN}$ & FP & FN & Sensitivity $(95 \% \mathrm{Cl})$ & Specificity $(95 \% \mathrm{Cl})$ & PPV $(95 \% \mathrm{Cl})$ & $\operatorname{NPV}(95 \% \mathrm{Cl})$ \\
\hline Microscopy & 57 & 632 & 0 & 82 & $\begin{array}{l}41.0 \\
32.7-49.7\end{array}$ & $\begin{array}{l}100 \\
99.4-100.0\end{array}$ & $\begin{array}{l}100 \\
99.4-100.0\end{array}$ & $\begin{array}{l}88.5 \\
87.0-89.9\end{array}$ \\
\hline Rapid diagnostic test & 91 & 632 & 0 & 48 & $\begin{array}{l}65.5 \\
56.9-73.3\end{array}$ & $\begin{array}{l}100 \\
99.4-100.0\end{array}$ & $\begin{array}{l}100 \\
99.4-100.0\end{array}$ & $\begin{array}{l}92.9 \\
91.3-94.3\end{array}$ \\
\hline crDNA-LAMP & 129 & 614 & 1 & 27 & $\begin{array}{l}82.6 \\
75.8-88.3\end{array}$ & $\begin{array}{l}99.8 \\
99.1-100.0\end{array}$ & $\begin{array}{l}99.2 \\
94.8-99.9\end{array}$ & $\begin{array}{l}95.8 \\
94.2-97.0\end{array}$ \\
\hline pDNA-LAMP & 133 & 630 & 2 & 6 & $\begin{array}{l}95.7 \\
90.1-98.4\end{array}$ & $\begin{array}{l}99.7 \\
98.8-99.9\end{array}$ & $\begin{array}{l}98.5 \\
94.3-99.6\end{array}$ & $\begin{array}{l}99.1 \\
97.9-99.6\end{array}$ \\
\hline
\end{tabular}

crDNA crude DNA extract, $p D N A$ purified DNA extract, sWGA selective whole genome amplification, $T P$ true positive, $T N$ true negative, $F P$ false positive, $F N$ false negative, $P P V$ positive predictive value, $N P V$ negative predictive value

(Table 3). Overall, microscopy detected 62.6\% (57/91) of all RDT positive results.

\section{Sensitivities, specificities and the predictive values of the diagnostic tests}

Using sWGA as reference assay, the respective sensitivities (95\% confidence interval) of malaria microscopy, RDT, crDNA-LAMP and pDNA-LAMP was $41.0 \%$ (32.7-49.7), 65.5\% (65.9-73.3), 82.6\% (75.8-88.3) and $95.7 \%(90.1-98.4)$. The specificities of microscopy and RDT were $100 \%$ but that of crDNA-LAMP and pDNALAMP were 99.8 and $99.7 \%$ respectively. The positive predictive values (PPV) calculated for microscopy and RDT were $100 \%$ whilst their respective negative predictive values (NPV) were $88.5 \%$ and $92.9 \%$. The PPV for crDNA-LAMP and PDNA-LAMP were 99.2\% and 98.5\% respectively while the NPV for crDNA-LAMP and pDNA-LAMP were $95.8 \%$ and $99.1 \%$ respectively (Table 4).

\section{Inter-diagnostic technique agreement}

Cohen's kappa analysis (Table 5) indicated substantial agreement between microscopy and RDT $(\kappa=0.74)$ whilst the agreement between microscopy and LAMP, and microscopy and sWGA were moderate (microscopy
Table 5 Cohen's kappa analysis of the diagnostic methods

\begin{tabular}{lllll}
\hline Kappa $(\mathbf{k})$ & Microscopy & RDT & crDNA-LAMP & pDNA-LAMP \\
\hline Microscopy & - & - & - & - \\
RDT & 0.74 & - & - & - \\
crDNA-LAMP & 0.56 & 0.78 & - & - \\
PDNA-LAMP & 0.54 & 0.77 & 0.91 & - \\
SWGA & 0.53 & 0.76 & 0.89 & 0.96 \\
\hline
\end{tabular}

Modified interpretation to kappa test statistic: $0.01-0.20$-slight agreement; 0.21-0.40-fair agreement; $0.41-0.60$-moderate agreement; $0.61-0.80$-substantial agreement; 0.81 -0.90-almost perfect agreement; 0.91-1.00-perfect agreement [21]

and crDNA-LAMP $\kappa=0.56$; microscopy and pDNALAMP $\kappa=0.54$ ) and the agreement between microscopy and sWGA assay was also moderate $(\kappa=0.53)$. There was substantial agreement between RDT, and LAMP and sWGA (RDT vs. crDNA-LAMP $\kappa=0.78$; RDT vs. pDNA-LAMP $\kappa=0.77$; RDT vs. sWGA $\kappa=0.76$ ). While crDNA-LAMP agreed perfectly with pDNA-LAMP $(\kappa=0.91)$, crDNA-LAMP almost agreed perfectly with sWGA $(\kappa=0.87)$ and pDNA-LAMP agreed perfectly with sWGA $(\kappa=0.96)$. 


\section{Discussion}

Plasmodium infections in blood donors are mostly asymptomatic due to competent anti-malaria immunity [30] which improves with age due to previous exposure with different strains of the parasite [31, 32]. Due to the competence of the anti-malarial immunity, $P$. falciparum parasite density in asymptomatic infections is mostly low [33]. In this study, microscopy technique missed 59.0\% of the overall asymptomatic $P$. falciparum infections indicating a high prevalence of sub-microscopic P. falciparum parasitaemia in blood donors. It was observed that microscopy could not detect parasitaemia less than 505 parasites/ $\mu \mathrm{L}$ of donor blood. Although microscopy is the goal standard for malaria parasites detection however, this widely used technique has low sensitivity with reported limit of detection between 10 and 100 parasites/ $\mu \mathrm{L}$ (approximately $0.0001 \%$ parasitaemia) [34-36] and it is also operator dependent [37]. Due to these limitations, it was not surprising that malaria microscopy could not detect close to $60 \%$ of $P$. falciparum infection in blood donors. The undetected parasite is likely to persist and provoke storage related cellular and immunological changes which when transfused could be inimical to the recipient.

Due to the aforementioned deficiencies of malaria microscopy, rapid diagnostic test kits (RDTs) were introduce in the 1990s to overcome limitations of microscopy [38]. In agreement with previous studies [34, 39-41], RDT detected 34 more infections than microscopy. However, sensitivity of the RDT was far less than sWGA and LAMP. In asymptomatic infections, the performance of RDTs have been found to be very poor due to very low parasite density [42, 43] and a study have reported decreased sensitivity due to high false-negative results associated with asymptomatic infections [44]. There was concordance between detection of $\mathrm{pLDH}$ and microscopy in all the 39 infections. The perfect agreement between $\mathrm{pLDH}$ and microscopy makes the detection of pLDH proteins in donor blood a surrogate biomarker for the presence of active and viable $P$. falciparum infections. This is because, Plasmodium LDH is known to be glycolytic pathway enzyme secreted by the different Plasmodium species. However, only metabolically active infections have been found to express pLDH [45] because pLDH has been reported in several studies to catalyze the inter-conversion of lactate into pyruvate to produce energy for parasite survivability and levels of pLDH in the blood is found to be directly related to Plasmodium density [46-49]. It was not surprising that there was absolute concordance between detection of $P$. falciparum LDH and microscopy. Notwithstanding the foregoing, $P$. falciparum specific LDH is a poor biomarker for detecting $P$. falciparum infections in the sense that, the enzyme has been found to disappear within $24 \mathrm{~h}$ of immune activation [50].

The reference selective whole genome amplification (sWGA) detected 139 infections while loop-mediated isothermal amplification assay based on crude DNA (crDNA-LAMP) and loop-mediated isothermal amplification assay based on purified DNA (pDNA-LAMP) detected 130 and 135 infections respectively. Similarly, sWGA, crDNA-LAMP and pDNA-LAMP detected 82, 56 and 78 sub-macroscopic infections, respectively. The agreement between the two LAMP assays and sWGA were almost perfect. Similar to results from previous reports $[51,52]$, this study found the sensitivity of LAMP assay to be very close to PCR variants. The LAMP assay has been shown to be sensitive enough to detect 1 malaria parasitized red cell [53] and has recently been used in field settings to detect malaria parasites [33, 52, 54] confirming the amenability of this molecular assay at low resourced setting. Although pDNA-LAMP and crDNA-LAMP agreed almost perfectly with the reference assay, the sensitivity of the former was higher than the latter. This could probably be due to high genomic DNA yield by the purified DNA extraction than the boil and spin DNA extraction method. This confirms why previous study suggested the use of high integrity DNA targets for LAMP assay because partial degradation or denaturing of target DNA in the process of specimen boiling during crude DNA extraction is a possibility [55]. Simplifying the DNA extraction protocol to obtain a good DNA yield will definitely make LAMP assay a reliable tool for detecting asymptomatic malaria infections in blood donors. And the perfect agreement, in spite of differences in their diagnostic performance, between crDNA-LAMP and pDNA-LAMP makes crude extraction of Plasmodium DNA in asymptomatic infection state reliable DNA source to detect asymptomatic malaria infections in blood donor using LAMP assay.

Moreover, Chi square goodness of fit analysis indicated non-significant differences between the performance of crDNA-LAMP and sWGA as well as between pDNALAMP and sWGA. Similarly, the differences between the diagnostic sensitivity of LAMP variants and sWGA in detecting sub-microscopy falciparum parasitaemia was also not significant.

Even though sWGA detected more infections than the LAMP assays, sWGA methodology is comparatively complex requiring equipment sophistication, expensive requiring highly-trained personnel and not amenable to low resource laboratories $[19,20]$. In the case of LAMP assay, simple incubators, such as a water baths, block heaters or thermal cyclers, are sufficient for DNA amplification [16] making LAMP assay employable in laboratories with limited resources in areas where 
malaria is endemic. LAMP assay has also been found to be more rapid, easy-to-perform and cost-effective procedure than PCR-based assays [56]. Again, several studies have reported on the field applicability of LAMP technology $[57,58]$ due to ease of visual readability of final reactions as a result of accumulation of magnesium pyrophosphate by-products [56]. Finally, LAMP assay has been further simplified by inventing a disc disposable chip that contain all reagents and buffers to perform the assay. The reagent is made of lyophilized amplification reagents and DNA extraction kit [59]. Commercialization of disc disposable LAMP-based chip and its applications in the field of malaria diagnosis will further improve on the merits of LAMP assay.

\section{Conclusion}

PCR based molecular assays remains the most reliable technique for detecting malaria parasites. Because in this study, sWGA detected most infections followed by the two LAMP assays. However, the two LAMP assays agreed perfectly with sWGA and statistically the differences in the performance of LAMP assays and sWGA in detecting asymptomatic malaria infections in blood donors were highly insignificant. However, due to the simplicity, cost-effectiveness, amenability to low resourced laboratory set-up, user-friendliness and applicability of LAMP assays to field settings as well as its rapid turnaround time, LAMP technique should be adopted for routine screening for asymptomatic $P$. falciparum infections prior to blood donation and/or transfusion.

\begin{abstract}
Abbreviations
18s-rRNA: 18 Svedberg ribosomal RNA; crDNA: crude DNA extract; FN: false negative; FP: false positive; LAMP: loop-mediated isothermal amplification; NPV: negative predictive value; pDNA: pure DNA extract; PfHRP2: P. falciparum histidine rich protein 2; PfHRP2-/pLDH ${ }^{+}$: pLDH but not PfHRP2 detected in donor blood; $\mathrm{PfHRP}^{+} / \mathrm{pLDH}^{-}$: PfHRP2 but not $\mathrm{pLDH}$ detected in donor blood; PfHRP2 ${ }^{+} / \mathrm{pLDH}^{+}$: both PfHRP2 and $\mathrm{pLDH}$ detected in donor blood; pLDH: Plasmodium lactate dehydrogenase; PPV: positive predictive value; RDT: rapid diagnostic test; sWGA: selective whole genome amplification; TN: true negative; TP: true positive; $\mathrm{k}$ : kappa.
\end{abstract}

\section{Acknowledgements}

The authors are thankful to Prof. Dominic Kwiatkowski, Dr Sonia Morgado Goncalves and Dr Cristina Ariani (Wellcome Sanger Institute, Hinxton, UK) for providing all the logistics needed to do the selective whole genome amplification. The collaborative roles of National Blood Service, Ghana and National Malaria Control Programme, Ghana are also appreciated. Finally, we appreciate the following individuals for the role they played during donor recruitment, sample collection and processing; Doreen Owusua-Ampedu, Dina Akuoko, Derrick Gyimah, Irene Ofosu, Gloria Nkasia Hisoon. Edmund Kwabena Danso, Osborne Nana Nyadze Aikins and Jude Lamptey.

\section{Authors' contributions}

EA, AE-Y, DOA conceived and designed the study and identified study collaborators. EA, SS-G supervised collection of donor specimens and performed the LAMP assay. EA performed the selective whole genome amplification. EA, AE-Y, DOA analysed data and drafted the manuscript. All authors read and approved the final manuscript.

\section{Funding}

Authors did not receive any financial support for this study.

\section{Availability of data and materials}

Study data have been deposited in Harvard Dataverse titled Replication Data for: 'Detecting asymptomatic P. falciparum in blood donors'", https://doi. org/10.7910/DVN/EACK5V.

\section{Ethics approval and consent to participate}

This study design conformed to the Helsinki Declaration and was approved by the Ghana Health Service Ethical Review Committee (GHS-REC002/03/18) and National Blood Service Research and Development, Ghana (NBSGRD/18903/01). All samples were collected after obtaining written informed consent from blood donors.

\section{Consent for publication}

Written inform consent was obtained from prospective blood donors for publication of their data. However, coded identifiers were used during specimen collection.

\section{Competing interests}

The authors declare that they have no competing interests.

\section{Author details}

${ }^{1}$ Department of Biomedical Sciences, School of Allied Health Sciences, University of Cape Coast, Cape Coast, Ghana. ${ }^{2}$ School of Biological Sciences, University of Ghana, Legon, Ghana. ${ }^{3}$ Department of Medical Laboratory Science, University of Cape Coast, Cape Coast, Ghana. ${ }^{4}$ Wellcome Sanger Institute, Hinxton CB10 1SA, UK.

Received: 15 March 2019 Accepted: 19 June 2019

Published online: 24 June 2019

\section{References}

1. Tiedje KE, Oduro AR, Agongo G, Anyorigiya T, Azongo D, Awine T, et al. Seasonal variation in the epidemiology of asymptomatic Plasmodium falciparum infections across two catchment areas in Bongo District, Ghana. Am J Trop Med Hyg. 2017;97:199-212.

2. Owusu-Ofori A, Gadzo G, Bates I. Transfusion-transmitted malaria: donor prevalence of parasitaemia and a survey of healthcare workers knowledge and practices in a district hospital in Ghana. Malar J. 2016;15:234-41.

3. Mogtomo ML, Fomekong SL, Kuate HF, Ngane AN. Screening of infectious microorganisms in blood banks in Douala (1995-2004). Sante. 2009; 19:3-8 (in French).

4. Diop S, Ndiaye M, Seck M, Knight B, Jambou R, Sarr A, et al. Prevention of transfusion transmitted malaria in endemic area. Transfus Clin Biol. 2009;16:454-9 (in French).

5. Kinde-Gazard, Oke J, Gnahoui I, Massougbodji A. The risk of malaria transmission by blood transfusion at Cotonou, Benin. Sante. 2000;10:389-92 (in French).

6. Oladeinde BH, Omoregie R, Osakue EO, Onaiwu TO. Asymptomatic malaria among blood donors in Benin City, Nigeria. Iranian J Parasitol. 2014;9:415-22.

7. Tagny CT, Mbanya D, Tapko J, Lefre're J. Blood safety in sub-Saharan Africa: a multi-factorial problem. Transfusion. 2008;48:1256-61.

8. Tapko JB, Mainuka P, Diarra-Nama AJ. Status of blood safety in the WHO Africa region. Mauritius: WHO Regional Office for Africa; 2009. https:// www.afro.who.int/sites/default/files/2017-06/status_blood_safety_who_ african_region.pdf. Accessed 14 Dec 2018.

9. Kitchen AD, Chiodini PL. Malaria and blood transfusion. Vox Sang. 2006:90:77-84. 
10. Erhabor O, Ok O, Awah I, Uko KE, Charles AT. The prevalence of plasmodia parasitaemia among donors in the Niger Delta of Nigeria. Trop Doct. 2007:37:32-4.

11. Sazama K. Prevention of transfusion-transmitted malaria: is it time to revisit the standards? Transfusion. 1991;31:786-8.

12. Chattopadhyay R, Majam VF, Kumar S. Survival of Plasmodium falciparum in human blood during refrigeration. Transfusion. 2011:51:630-5.

13. Aninagyei E, Doku TE, Adu P, Egyir-Yawson A, Acheampong OD. Storage related haematological and biochemical changes in Plasmodium falciparum infected and sickle cell trait donor blood. BMC Hematol. 2018;18:30.

14. Arcanjo AR, Lacerda MV, Alecrim WD, Alecrim MG. Evaluation of the Optimal-IT ${ }^{\circledR}$ and ICT P.f./P.v. ${ }^{\circledR}$ rapid dipstick tests for diagnosing malaria within primary healthcare in the municipality of Manaus. Amazonas Rev Soc Bras Med Trop. 2007:40:88-90.

15. Nansseu JRN, Noubiap JJN, Ndoula ST, Zeh AFM, Monamele CG. What is the best strategy for the prevention of transfusion-transmitted malaria in sub-Saharan African countries where malaria is endemic? Malar J. 2013;12:465.

16. Notomi T, Okayama H, Masubuchi H, Yonekawa T, Watanabe K, Amino N, et al. Loop-mediated isothermal amplification of DNA. Nucleic Acids Res. 2000;28:63-5.

17. Larremore DB, Sundararaman SA, Liu W, Proto WR, Clauset A, Loy DE, et al. Ape parasite origins of human malaria virulence genes. Nat Commun. 2015;6:8368.

18. Sundararaman SA, Plenderleith LJ, Liu W, Loy DE, Learn GH, Li Y, et al. Genomes of cryptic chimpanzee Plasmodium species reveal key evolutionary events leading to human malaria. Nat Commun. 2016;7:11078.

19. Guggisberg AM, Sundararaman SA, Lanaspa M, Moraleda C, González R, Mayor A, et al. Whole genome sequencing to evaluate the resistance landscape following antimalarial treatment failure with fosmidomycinclindamycin. J Infect Dis. 2016;214:1085-91.

20. Leichty AR, Brisson D. Selective whole genome amplification for resequencing target microbial species from complex natural samples. Genetics. 2014;198:473-81.

21. Dean FB, Hosono S, Fang L, Wu X, Faruqi AF, Bray-Ward P, et al. Comprehensive human genome amplification using multiple displacement amplification. Proc Natl Acad Sci USA. 2002;99:5261-6.

22. Fuller CW, Middendorf LR, Benner SA, Church GM, Harris T, Huang $X$, et al. The challenges of sequencing by synthesis. Nat Biotechnol. 2009;27:1013-23.

23. Sathpathi S, Mohanty AK, Satpathi P, Mishra SK, Behera PK, Patel G, et al. Comparing Leishman and Giemsa staining for the assessment of peripheral blood smear preparations in a malaria-endemic region in India. Malar J. 2014;13:512.

24. WHO. Basic Malaria Microscopy: Part I Learner's Guide. Geneva, World Health Organization; 1991. https://www.who.int/malaria/publications/ atoz/9241547820/en/. Accessed 4 Jan 2019.

25. WHO, FIND, CDC, TDR. Malaria rapid diagnostic test performance: results of WHO product testing of malaria RDTs: Round3 (2010-2011). Geneva: World Health Organization; 2011.

26. Poon LL, Wong BW, Ma EH, Chan KH, Chow LM, Abeyewickreme W, et al Sensitive and inexpensive molecular test for falciparum malaria: detecting Plasmodium falciparum DNA directly from heat-treated blood by loop-mediated isothermal amplification. Clin Chem. 2006;52:303-6.

27. Oyola SO, Ariani CV, Hamilton WL, Kekre M, Amenga-Etego LN, Ghansah A, et al. Whole genome sequencing of Plasmodium falciparum from dried blood spots using selective whole genome amplification. Malar J. 2016:15:597.

28. Li H, Durbin R. Fast and accurate short read alignment with BurrowsWheeler transform. Bioinformatics. 2009:25:1754-60.

29. Li H, Handsaker B, Wysoker A, Fennell T, Ruan J, Homer N, Marth G, et al. Genome project data processing $\mathrm{S}$ : the sequence alignment/map format and SAM tools. Bioinformatics. 2009;25:2078-9.

30. Belizario VY, Saul A, Bustos MD, Lansang MA, Pasay CJ, Gatton M, et al. Field epidemiological studies on malaria in a low endemic area in the Philippines. Acta Trop. 1997;63:241-56.

31. Gupta S, Trenholme K, Anderson RM, Day KP. Antigenic and the transmission dynamics of Plasmodium falciparum. Science. 1994;263:961-3.

32. Hastings IM. Population genetics and the detection of immunogenic and drug-resistant loci in Plasmodium. Parasitology. 1996;112:155-64.
33. Sattabongkot J, Tsuboi T, Han ET, Bantuchai S, Buates S. Loop-mediated isothermal amplification assay for rapid diagnosis of malaria infections in an area of endemicity in Thailand. J Clin Microbiol. 2014;52:1471-7.

34. Moody A. Rapid diagnostic tests for malaria parasites. Clin Microbiol Rev. 2002;15:66-78.

35. Wongsrichanalai C, Barcus MJ, Muth S, Sutamihardja A, Wernsdorfer WH. A review of malaria diagnostic tools: microscopy and rapid diagnostic test (RDT). Am J Trop Med Hyg. 2007;77:119-27.

36. Wu L, van den Hoogen LL, Slater H, Walker PG, Ghani AC, Drakeley CJ, et al. Comparison of diagnostics for the detection of asymptomatic Plasmodium falciparum infections to inform control and elimination strategies. Nature. 2015;528:586-93.

37. Payne D. Use and limitations of light microscopy for diagnosing malaria at the primary health care level. Bull World Health Organ. 1988;66:621-6.

38. Mason DP, Kawamoto F, Lin K, Laoboonchai A, Wongsrichanalai C. A comparison of two rapid field immunochromatographic tests to expert microscopy in the diagnosis of malaria. Acta Trop. 2002;82:51-9.

39. Palmer CJ, Lindo JF, Klaskala WI, Quesada JA, Kaminsky R, Baum MK, et al. Evaluation of the OptiMAL test for rapid diagnosis of Plasmodium vivax and Plasmodium falciparum malaria. J Clin Microbiol. 1998;36:203-6.

40. Jelinek T, Grobusch MP, Nothdurft HD. Use of dipstick tests for the rapid diagnosis of malaria in nonimmune travelers. J Travel Med. 2000;7:175-9.

41. Azikiwe CC, Ifezulike CC, Siminialayi IM, Amazu LU, Enye JC, Nwakwunite OE. A comparative laboratory diagnosis of malaria: microscopy versus rapid diagnostic test kits. Asian Pac J Trop Biomed. 2012;2:307-10.

42. Shekalaghe SA, Bousema JT, Kunei KK, Lushino P, Masokoto A, Wolters $L R$, et al. Submicroscopic Plasmodium falciparum gametocyte carriage is common in an area of low and seasonal transmission in Tanzania. Trop Med Int Health. 2007:12:547-53.

43. Mens P, Spieker N, Omar S, Heijnen M, Schallig H, Kager PA. Is molecular biology the best alternative for diagnosis of malaria to microscopy? A comparison between microscopy, antigen detection and molecular tests in rural Kenya and urban Tanzania. Trop Med Int Health. 2007;12:238-44.

44. Murray CK, Gasser RA, Magill AJ, Miller RS. Update on rapid diagnostic testing for malaria. Clin Microb Rev. 2008;21:97-110.

45. Harani MS, Beg MA, Khaleeq L, Adil SN, Kakepoto GN, Khurshid M. Role of ICT malaria immunochromatographic test for rapid diagnosis of malaria. J Pak Med Assoc. 2006;56:167-71.

46. Cho CH, Nam MH, Kim JS, Han ET, Lee WJ, Oh JS, et al. Genetic variability in Plasmodium vivax aldolase gene in Korean isolates and the sensitivity of the Binax Now malaria test. Trop Med Int Health. 2011;16:223-6.

47. Baker J, McCarthy J, Gatton M, Kyle DE, Belizario V, Luchavez J, et al. Genetic diversity of Plasmodium falciparum histidine-rich protein 2 (PfHRP2) and its effect on the performance of PfHRP2-based rapid diagnostic tests. J Infect Dis. 2005;192:870-7.

48. Brown WM, Yowell CA, Hoard A, Vader Jagt TA, Hunsaker LA, Deck LM, et al. Comparative structural analysis and kinetic properties of lactate dehydrogenases from the four species of human malarial parasites. Biochem. 2004;43:6219-29.

49. Piper R, Lebras J, Wentworth L, Hunt-Cooke A, Houze S, Chiodini P, et al. Immunocapture diagnostic assays for malaria using Plasmodium lactate dehydrogenase (pLDH). Am J Trop Med Hyg. 1999;60:109-14.

50. Oduola AM, Omitowoju GO, Sowunmi A, Makler MT, Falade CO, Kyle $\mathrm{DE}$, et al. Plasmodium falciparum: evaluation of lactate dehydrogenase in monitoring therapeutic responses to standard antimalarial drugs in Nigeria. Exp Parasitol. 1997;87:283-9.

51. Polley SD, González IJ, Mohamed D, Daly R, Bowers K, Watson J, et al. Clinical evaluation of a loop-mediated amplification kit for diagnosis of imported malaria. J Infect Dis. 2013;208:637-44.

52. Aydin-Schmidt B, Xu W, González IJ, Polley SD, Bell D, Shakely D, et al. Loop mediated isothermal amplification (LAMP) accurately detects malaria DNA from filter paper blood samples of low density parasitaemias. PLoS ONE. 2014;9:e103905.

53. Buates S, Bantuchai S, Sattabongkot J, Han ET, Tsuboi T, Udomsangpetch $\mathrm{R}$, et al. Development of a reverse transcription-loop-mediated isothermal amplification (RT-LAMP) for clinical detection of Plasmodium falciparum gametocytes. Parasitol Int. 2010;59:414-20.

54. Cook J, Aydin-Schmidt B, Gonzalez IJ, Bell D, Edlund E, Nassor MH, et al. Loop-mediated isothermal amplification (LAMP) for point-of-care detection of asymptomatic low-density malaria parasite carriers in Zanzibar. Malar J. 2015;14:43. 
55. Bista BR, Ishwad C, Wadowsky RM, Manna P, Randhawa PS, Gupta G, et al. Development of a loop-mediated isothermal amplification assay for rapid detection of BK virus. J Clin Microbiol. 2007:45:1581-7.

56. Mori Y, Nagamine K, Tomita N, Notomi T. Detection of loop-mediated isothermal amplification reaction by turbidity derived from magnesium pyrophosphate formation. Biochem Biophys Res Commun. 2001;289:150-4.

57. Ablordey A, Amissah DA, Aboagye IF, Hatano B, Yamazaki T. Detection of Mycobacterium ulcerans by the loop mediated isothermal amplification method. PLoS Negl Trop Dis. 2012;6:e1590.
58. De-Souza DK, Quaye C, Mosi L, Addo P, Boakye DA. A quick and cost effective method for the diagnosis of Mycobacterium ulcerans infection. BMC Infect Dis. 2012;12:8.

59. WHO. Fever diagnostic technology landscape. 1st ed. Geneva: World Health Organization; 2018.

\section{Publisher's Note}

Springer Nature remains neutral with regard to jurisdictional claims in published maps and institutional affiliations.
Ready to submit your research? Choose BMC and benefit from:

- fast, convenient online submission

- thorough peer review by experienced researchers in your field

- rapid publication on acceptance

- support for research data, including large and complex data types

- gold Open Access which fosters wider collaboration and increased citations

- maximum visibility for your research: over 100M website views per year

At BMC, research is always in progress.

Learn more biomedcentral.com/submissions 